\title{
Solid Pulmonary Masses Simulating Vascular Tumors
}

\author{
Mujahid M. Salim, M.D., Faroque A. Khan, M.B., FACP, FCCP, Amatal B. Mir, M.B. \\ Jamaica, New York
}

DOI: http://dx.doi.org/10.5915/19-3-13017

\begin{abstract}
:
An asymptomtic male presented with multiple pulmonary parenchymal masses on chest roentgenography. CT showed three high attenuation masses. A vascular mass was considered but an angiogram subsequently done was negative. Lymphadenopathy was noted at this point and a biopsy showed a low grade neuroendocrine carcinoma. Thus some solid tumors simulate vascular masses. Vascular masses too may present as solid tumors and an angiogram is mandatory for diagnosis.
\end{abstract}

Key Words: Metastasis, Multiple nodules, Computerized tomography

Some solid pulmonary parenchymal tumors simulate vascular lesions and appear as high attenuation masses on computed tomography. The case history of a patient with a similar tumor is presented here.

\section{Case History}

A thirty-five year old male, non smoker, presented with a history of intermittent dry cough for one month. He denied fever, weight loss or chest pain. A chest roentgenogram performed three years ago was normal. Physical examination revealed no cardiac murmurs, clear lung fields and no lymphadenopathy was present. The hematocrit was 48 percent and the white cell count was $6,200 \mathrm{~mm}^{3}$. An arterial blood gas analysis showed $\mathrm{pH} 7.4, \mathrm{PCO}_{2} 34 \mathrm{mmHg}, \mathrm{PO}_{2}$ $88 \mathrm{mmHg}$, and $\mathrm{O}_{2}$ saturation of 97 percent. A chest roentgenogram revealed two large right perihilar masses with one smaller parenchymal density (Fig. 1). Computerized tomography showed three sharply

From the Division of Pulmonary Medicine, Department of Medicine, Queens Hospital Center Affiliation of the Long Island Jewish Medical Center and School of Medicine, Health Sciences Center at the State University of New York at Stony Brook, New York

Reprint requests:

Mujahid M. Salim, M.B.,

Division of Pulmonary Medicine,

Queens Hospital Center.

82-68 I64th Street,

Jamaica, NY 11432 ,

(718) $990-3601$ defined high attenuation masses in continuation with the vascular tree (Fig. 2).

\section{Differential Diagnosis:}

A-V malformations, pulmonary artery aneurysms, pulmonary varices, and coarctation of the pulmonary arteries were considered amongst the differential diagnoses.

An A-V fistula is an abnromal communication between an artery and a vein, the capillary network being absent. The incidence is $1: 115$ of solitary nodules and the average age of onset is 35 years. Multiple lesions are present $35-50$ percent of the time, and are bilateral in 8-20 percent of the cases. If more than 20 percent shunt is present, signs and symptoms such as cyanosis (60 percent), clubbing, polycythemia, epistaxis, resting hyperventilation, dyspnea (44 percent), hematuria, melena, hemoptysis, headache, vertigo, syncope, and mucocutaneous telangiectasis (33 percent) of face, lips, buccal mucosa, nail beds and skin may occur. Laboratory examination shows polycythemia ( 50 percent), increased cardiac output, orthodeoxia, reticulocytosis and an oxygen saturation of 57-88 percent. Radiography shows a lower lobe predominance, usually circumscribed, noncalcified lesions 1-2 centimeter in size with visible draining vessels. Pulmonary function test show increased shunting at TLC, radionuclide ventriculography shows a hot spot while a lung scan reveals a cold spot. Angiography confirms the diagnosis. None of these signs or symptoms were present in our patient, ruling out the presence of an A-V fistula.

Pulmonary artery aneurysms on the other hand 


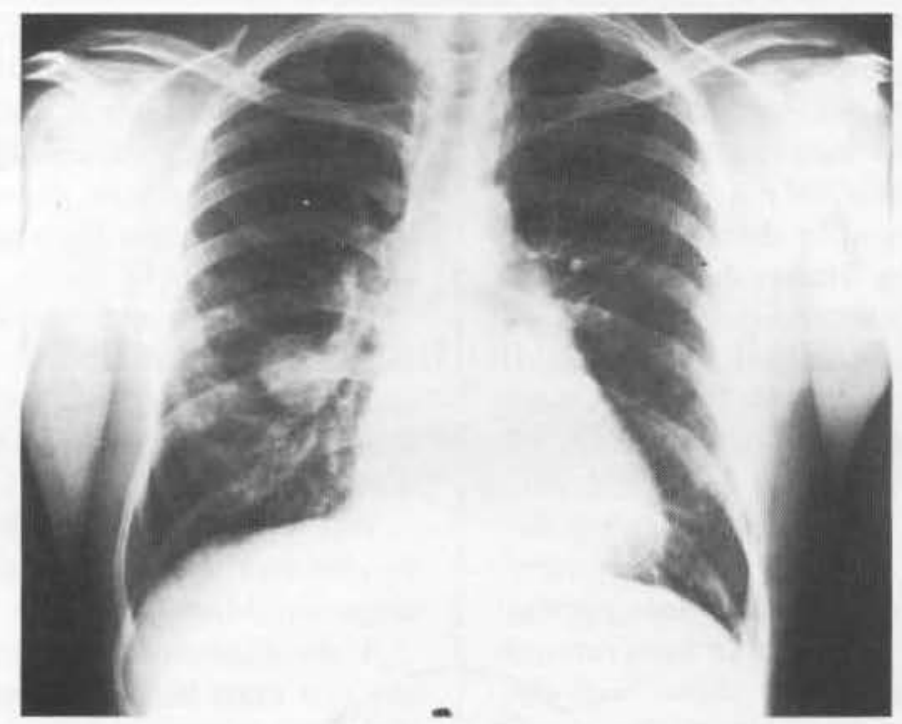

Figure 1: Chest roentgenogram showing three perihilar densities.

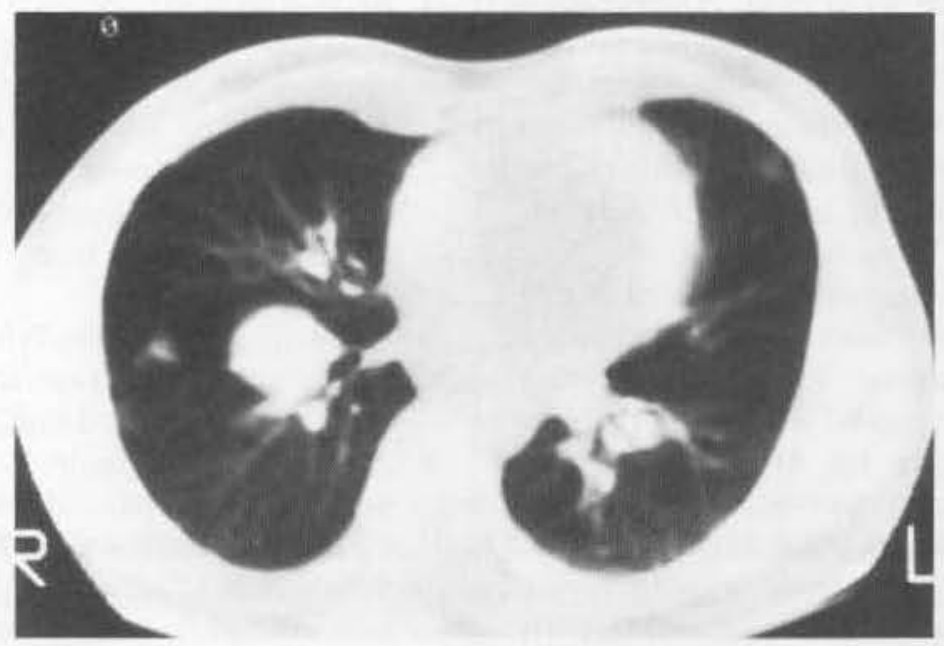

Figure 2: CT chest showing high attenuation masses in conjunction with the vascular tree.

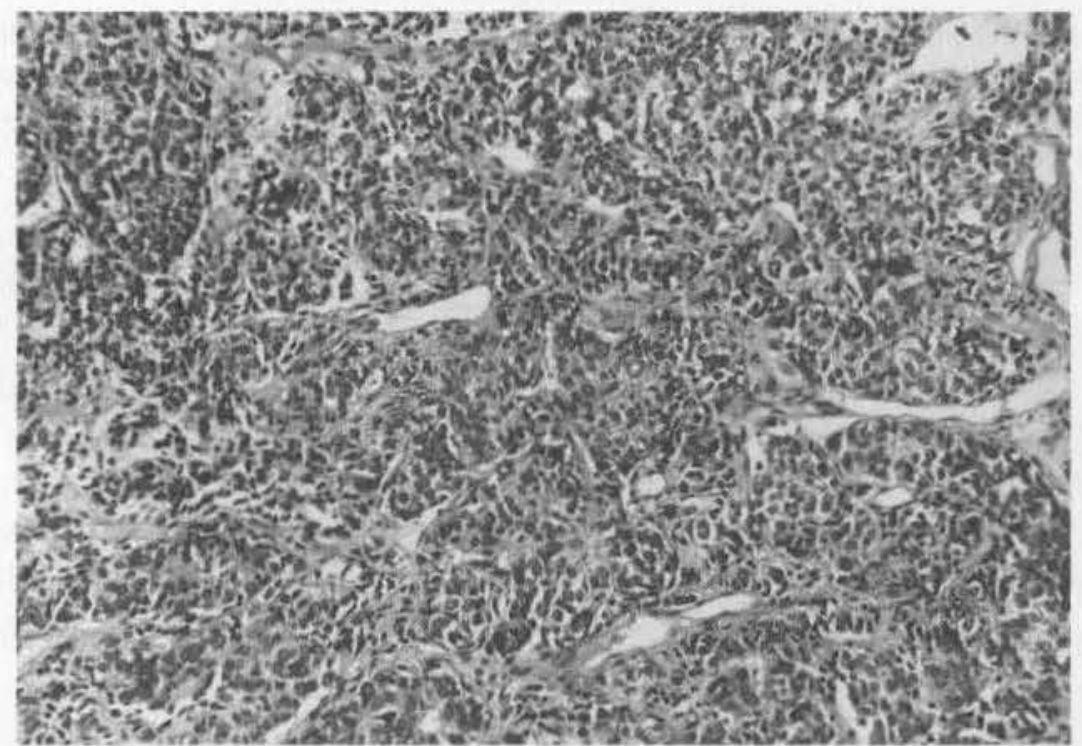

Figure 3: Microscopic picture showing carcinoid. 
present with signs and symptoms which include chest pain (17 percent), dyspnea on exertion (69 percent), cough ( 37 percent), hemoptysis ( 31 percent), cyanosis ( 57 percent), edema (40 percent), an asymptomatic harsh systolic murmur, precordial pulsations, thrills, and a loud $P_{2}$. Chest radiography shows a peripheral coin lesion or pulmonary trunk dilatation with definite vascular connections. Angiography shows opacification of mass in the arterial phase of contrast. All these signs and symptoms, however, were absent in our patient ruling out the presence of arterial aneurysms.

Pulmonary varices were considered next. Only fifty cases have been reported in the world literature. These patients may be asymptomatic or may present with hemoptysis, dyspnea, embolism or fatal rupture of the varices. Chest radiography shows well circumscribed lobular lesions usually right sided, predominantly in the upper lobe though occasionally in the middle third of either lung field. Lung compression or atelectasis may be present. Angiography shows opacification of the mass in the venous phase of contrast. As none of these signs and symptoms were present, this entity was ruled out.

The shunt and mediastinal flow studies as well as the angiogram were normal in our patient, thus ruling out the possibility of a vascular mass.

Right cervical lymphadenopathy was noted at this point and a biopsy was done. Light microscopy showed nests of pleomorphic cells with moderate mitosis. Reticulin stain revealed a cell nest pattern. Immunoperoxidase studies for HCG, alpha-fetoprotein and serotonin were negative, though neuronspecific enolase was focally positive (Fig. 3).

Thus the diagnosis of a low grade neuroendocrine carcinoma (bronchopulmonary carcinoid) with metastasis was made. ${ }^{2}$

\section{Comment:}

These bronchopulmonary carcinoids give rise to metastatic disease in upto 73 percent of the cases. ${ }^{4}$ CT has proven a better modality than bronchoscopy in the evaluation of these "Iceberg" lesions., " They are central tumors, near the segmental bronchi, and can give rise to obstruction with peripheral pneumonitis. Hyperplastic lymphadenopathy can occur secondary to repeated infections, and can be mistaken for metastatic involvement of these lymph nodes." Rapid sequence (dynamic) computed Iomography has been shown to be helpful in differentiating vascular from non-vascular lesions of the lung. ${ }^{\text {? }}$

This unusual cases shows the problem of solid masses such as bronchopulmonary carcinoids, cystic nodular sclerosing Hodgkin's disease, metastatic sarcomas, hamartomas, and some genitourinary tumors simulating vascular lesions.

Vascular lesions like pulmonary varices and $\mathrm{A}-\mathrm{V}$ fistulae on the other hand can be mistaken for hilar disease and tumors.

A bronchopulmonary carcinoid simulating a vascular mass has only been reported once before in the world literature.

\section{References:}

1. Aron Chick JM, Wexler JA, Christen B, Miller W, Epstein D, Gefter WB: Computed tomography of bronchial carcinoid. J Comput Assist Tomogr 1986; 10:71-74.

2. Warren NH, Gould VE, Faber LP, Kittle CF, Memoli VA: Neuroendocrine neoplasms of the bronchopulmonary tract. Thorac Cardiovasc Surg $1985 ; 89: 819-825$.

3. Godwin JD, Webb WR: Dynamic computed tomography in the evaluation of vascular lung lesions. Radiol 1981; 138:629-635.

4. Naidich DP, McCauley DI, Siegelman SS: Computed tomography of bronchial adenomas. J Comput Assist Tomogr 1982; 6:725-732.

5. Webb WR, Gamsu G, Birnberg FA: CT appearance of bronchial carcinoid with recurrent pneumonia and hyperplastic hilar lymphadenopathy. J Comput Assist Tomogr 1983; 7:707-709.

6. Kilgore TL, Chasen MH: Pulmonary arteriovenous fistula simulating a vanishing I umor. South Med J 1983; 76:884-886. 